\title{
Fungal-host interactions: insights into microRNA in response to Paracoccidioides species
}

\author{
Junya de Lacorte Singulani', Julhiany de Fátima da Silva', Fernanda Patricia Gullo', \\ Marina Célia Costa ${ }^{2}$, Ana Marisa Fusco-Almeida', Francisco Javier Enguita ${ }^{2}$, \\ Maria José Soares Mendes-Giannini¹++
}

${ }^{1}$ Universidade Estadual Paulista, Faculdade de Ciências Farmacêuticas, Araraquara, SP, Brasil

${ }^{2}$ Universidade de Lisboa, Faculdade de Medicina, Instituto de Medicina Molecular, Lisboa, Portugal

BACKGROUND Paracoccidioides spp. causes paracoccidioidomycosis (PCM), an important and frequent systemic mycosis that occurs in Latin America. The infectious process begins with contact between the fungus and lung cells, and the molecular pattern of this interaction is currently poorly understood. MicroRNAs (miRNAs) are small non-coding RNAs that regulate the gene expression in many biological processes, including in the infections.

OBJECTIVE This study aimed to analyse the expression of miRNAs in lung cells as response to infection by Paracoccidioides spp.

METHODS A quantitative real-time polymerase chain reaction (RT-qPCR) based screening was employed to verify differentially expressed miRNAs in human lung cells infected with three different species; Paracoccidioides lutzii, Paracoccidioides americana, and Paracoccidioides brasiliensis. Furthermore, the in silico predictions of target genes and pathways for miRNAs were obtained.

FINDINGS The results showed that miRNAs identified in the lung cells were different according to the species studied. However, based on the predicted targets, the potential signaling pathways regulated by miRNAs are common and related to adhesion, actin cytoskeleton rearrangement, apoptosis, and immune response mediated by T cells and TGF- $\beta$.

MAIN CONCLUSIONS In summary, this study showed the miRNAs pattern of epithelial cells in response to infection by Paracoccidioides species and the potential role of these molecules in the regulation of key pathogenesis mechanisms of PCM.

Key words: paracoccidioidomycosis - microRNAs - pathways - target genes - lung cells

Paracoccidioidomycosis (PCM) is a systemic mycosis, endemic in Latin America. This mycosis is acquired after inhalation of conidia of dimorphic fungus Paracoccidioides spp. and the infectious process begins in the lungs of patients, but the fungus can spread to other organs. ${ }^{(1)}$ The Paracoccidioides genus is composed of a clade with five phylogenetic species: Paracoccidioides brasiliensis (S1a, S1b, PS2, PS3, and PS4) and a Paracoccidioides lutzii clade. ${ }^{(2,3)}$ Recently, a new taxonomic description was suggested, wherein phylogenetic species PS2, PS3, and PS4 were reclassified as species Paracoccidioides americana, Paracoccidioides restrepiensis and Paracoccidioides venezuelensis, respectively. ${ }^{(4)}$ In this context, the correct molecular taxonomy of these fungi has opened new possibilities for studying and understanding their relationships with their hosts. ${ }^{(5)}$

MicroRNAs or miRNAs are small non-coding RNAs with approximately 22 nucleotides that are expressed by all metazoan eukaryotes and have emerged as major

doi: 10.1590/0074-02760200238

Financial support: CAPES/Fundação para a Ciência e a Tecnologia (CAPES/FCT grant no. 345/13), FAPESP (grant no. 2014/10446-9 - PhD fellowship), CNPq.

JLS and JFS contributed equally to this work.

+ Corresponding author: gianninimj@gmail.com / giannini@fcfar.unesp.br

(D) https://orcid.org/0000-0002-8059-0826

Received 15 May 2020

Accepted 22 July 2020 controllers of gene expression of at least $30 \%$ of human genes. They mediate the regulation of gene expression in response to pathogen infection and are known to be the primary regulators of an immune response. ${ }^{(6,7,8)}$ In this context, differential expression of miRNAs has been described in response to infections by fungi such as Candida albicans, ${ }^{(9)}$ Aspergillus fumigatus, ${ }^{(10)}$ and Cryptococcus neoformans. ${ }^{(11)}$

In previous studies, the expressions of miRNAs in the lung tissues of mice infected by $P$. brasiliensis $^{(12)}$ and in the serum of patients with $\mathrm{PCM}^{(13)}$ were analysed. In this study, we analysed the expression of miRNAs directly in human lung cells in response to infection by different species of the genus Paracoccidioides.

\section{MATERIALS AND METHODS}

Infection and extraction of RNAs - Three species; $P$. lutzii 01 (ATCC MYA-826, Goiânia), P. americana 02 (Venezuela), and P. brasiliensis 18 (São Paulo) from the collection of the Laboratory of Clinical Mycology, Faculty of Pharmaceutical Sciences of UNESP, Araraquara (Brazil) were used in this study. The fungi were maintained in Fava-Netto medium at $37^{\circ} \mathrm{C}$ and were used after three to four days of growth.

The human A549 lung carcinoma cell line was obtained commercially (Code: 0033; Banco de células do Rio de Janeiro - BCRJ, Federal University of Rio de Janeiro, Brazil). The cells were maintained in HAM F-12 medium, supplemented with $10 \%$ fetal bovine serum at $37^{\circ} \mathrm{C}$ in a $5 \% \mathrm{CO}_{2}$ atmosphere. 
For the experiments, cells (adjusted to $10^{4}$ cells $/ \mathrm{mL}$ ) were grown in $75 \mathrm{~mm}^{3}$ cell culture flasks for $24 \mathrm{~h}$ in HAM F-12 medium supplemented with $10 \%$ foetal bovine serum at $37^{\circ} \mathrm{C}$ and $5 \% \mathrm{CO}_{2}$ to reach at least $80 \%$ confluence. Then, lung cells were incubated with $10^{6}$ cells $/ \mathrm{mL}$ of each fungal species (multiplicity of infection - MOI 100:1) at $37^{\circ} \mathrm{C}$ for $5 \mathrm{~h}$. After, the cells were washed with phosphate-buffered saline (PBS) to remove the unbound fungi. Uninfected lung cells were used as control. Samples were immediately frozen at $-80^{\circ} \mathrm{C}$. The experiments were carried out in triplicate, and at least three independent experiments were performed.

The extraction of RNA was performed using Trizol (Invitrogen) followed by purification using the RNeasy Mini Kit (Qiagen) according to the manufacturer's instructions. The concentration of total RNA was determined at $260 \mathrm{~nm}$ using NanoDrop 2000/2000c and the RNA integrity was analysed using a Bioanalyzer Agilent 2100.

Complementary DNA (cDNA) synthesis and quantitative real-time polymerase chain reaction (RT-qPCR) - cDNA synthesis of mRNA was performed with Universal a cDNA Synthesis kit (Exiqon A/S) according to the manufacturer's instructions. After, quantification of miRNAs was performed by RT-qPCR with SYBR Green PCR Master Mix (Exiqon A/S) at a total reaction volume of $80 \mu \mathrm{L}$. Then, $10 \mu \mathrm{L}$ of the reaction mixture was added to each well of a panel (microRNA Readyto-Use PCR, Human panel I+II, V.2 M/R; Exiqon A/S), which contained specific primers for 752 unique human miRNAs. Amplification was performed using a Vii $\mathrm{A}^{\mathrm{TM}} 7$ Real-Time PCR System (Thermo Fisher Scientific, Inc., Waltham, MA, USA) followed by the determination of the melting curve. Cycling conditions were $95^{\circ} \mathrm{C}$ for 10 min followed by 40 cycles of $95^{\circ} \mathrm{C}$ for $10 \mathrm{~s}$ and $60^{\circ} \mathrm{C}$ for 60 s. Expression profiling of miRNAs was calculated using the $\Delta \Delta \mathrm{Ct}$ method, ${ }^{(14)}$ with $\Delta \Delta \mathrm{Ct}$ as the difference between infected and non-infected cells. The endogenous controls UniSp6, U6 snRNA, SNORD38B and SNORD49A were used to normalise the analysis in each sample. Statistical analysis was performed using DataAssist v2 Software (Applied Biosystems; Thermo Fisher Scientific, Inc.) and $\mathrm{p}<0.05$ was considered statistically significant.

Pathways analysis - Predicted miRNA targets and potential infection pathways for miRNAs were obtained using the DIANA miRNA and mirPath tools ${ }^{(15)}$ and functional KEGG pathway database. ${ }^{(16)}$

\section{RESULTS}

In this study, several miRNAs among 752 human miRNAs analysed were differentially expressed in A459 lung cells after infection with Paracoccidioides spp. A period of $5 \mathrm{~h}$ of infection was selected because a previous study demonstrated a higher percentage of infected A549 cells by $P$. brasiliensis at this time compared to others $(2,18,24$ and $48 \mathrm{~h})$. In addition, after $5 \mathrm{~h}$, the process of apoptosis in A549 cells gradually increased up to $48 \mathrm{~h}$, reducing the cell viability. ${ }^{(17)}$ The data generated by RT-qPCR $(\mathrm{p}<0.05$ and fold-change $\geq 2)$ showed that miRNAs expressed in lung cells were different ac- cording to the phylogenetic species of the fungus. Most miRNAs (8) were downregulated in the cells infected with P. lutzii (P101) compared to non-infected cells (Table I). On the other hand, most miRNAs (21) were up regulated in infected cells with $P$. americana $02(\mathrm{~Pa} 02)$ compared to the control (Table II). In the cells infected with $P$. brasiliensis 18 (Pb18), eight miRNAs were upregulated and 10 miRNAs down-regulated compared to the control (Table III).

A Venn diagram was employed to identify overlapping miRNAs (Fig. 1). The miR-92a and miR-941 were common between human lung cells infected with $\mathrm{Pb} 18$ or Pa02, while miR-26b-5p, miR-379-5p, and miR-185$5 \mathrm{p}$ were common and down-regulated in human lung cells infected with P101 or Pb18.

After, we performed in silico analysis of the possible pathways regulated by the set of miRNAs in each case. Gene targets analysis for the differentially expressed miRNAs in the cells infected with each species of Paracoccidioides was performed using DIANA miRNA and miRPath tools. The number of predicted target genes varied from 109 (miR-24-1-5p) to 953 (miR-26b-5p) in the cells infected with P. lutzii; from 0 (miR-181a-3p) to 1574 (miR-7-2-3p) in the cells infected with P. americana; and from 22 (miR-1538) to 1330 (miR-27a-3p) in the cells infected with P. brasiliensis (Fig. 2).

Subsequently, pathway analysis considering specifically the cell infection processes demonstrated that although miRNAs identified in the lung cells were different according to the species studied, the potential pathways regulated by miRNAs were common. The identified pathways were related to the process of adhesion between the fungus and the cell (focal adhesion, Rap1 signaling pathway, adherens and GAP junctions); the invasion process (endocytosis and rearrangement of the actin cytoskeleton); the immune response ( $\mathrm{T}$ cell receptor, Wnt and MAPK signaling pathways), and the induction of apoptosis (MAPK, p53, TGF $\beta$ and Hippo signaling pathways) (Table IV).

TABLE I

Differentially expressed miRNAs in human lung cells infected with Paracoccidioides lutzii (P101)

\begin{tabular}{lcc}
\hline Upregulated & Fold change & $p$ value \\
\hline miR-1911-3p & 2.12 & 0.0496 \\
\hline Downregulated & Fold change & p value \\
\hline miR-940 & 0.55 & 0.0275 \\
\hline miR-26b-5p & 0.52 & 0.0422 \\
\hline miR-379-5p & 0.49 & 0.0020 \\
\hline miR-146a-5p & 0.47 & 0.0104 \\
\hline miR-17-5p & 0.41 & 0.0178 \\
\hline miR-185-5p & 0.39 & 0.0304 \\
\hline miR-454-3p & 0.31 & 0.0441 \\
\hline miR-24-1-5p & 0.29 & 0.0331 \\
\hline
\end{tabular}


TABLE II

Differentially expressed miRNAs in human lung cells infected with Paracoccidioides americana 02 (Pa02)

\begin{tabular}{lcc}
\hline Upregulated & Fold change & p value \\
\hline miR-92a-1-5p & 5.80 & 0.0075 \\
\hline miR-20a-3p & 3.47 & 0.0076 \\
\hline miR-125b-1-3p & 2.85 & 0.0342 \\
\hline miR-181a-3p & 2.83 & 0.0305 \\
\hline miR-125a-3p & 2.63 & 0.0224 \\
\hline miR-941 & 2.60 & 0.0053 \\
\hline miR-542-5p & 2.52 & 0.0345 \\
\hline miR-1245 & 2.45 & 0.0265 \\
\hline miR-18a-5p & 2.44 & 0.0343 \\
\hline miR-187-3p & 2.37 & 0.0262 \\
\hline miR-639 & 2.27 & 0.0322 \\
\hline miR-506-3p & 2.27 & 0.0322 \\
\hline miR-195-3p & 2.26 & 0.0216 \\
\hline miR-153 & 2.24 & 0.0332 \\
\hline miR-432-3p & 2.21 & 0.0040 \\
\hline miR-200a-3p & 2.20 & 0.0395 \\
\hline miR-1267 & 2.20 & 0.0402 \\
\hline miR-769-5p & 2.17 & 0.0148 \\
\hline miR-7-2-3p & 2.13 & 0.0428 \\
\hline miR-950 & 2.11 & 0.03418 \\
\hline miR-9-5p & 0.47 & \\
\hline & & 0.07 \\
\hline
\end{tabular}

In addition, we found that 89 predicted genes could be targeted by eight or more miRNAs from the different studied species (Fig. 3). Among them, $\mathrm{CDH} 23, \mathrm{CD} 2 \mathrm{AP}$, and TPM1 could be related to fungus adhesion and invasion to cell, while CCNL2, RAD51B and BRW1 could have a role in apoptosis, and TNFSF8, NFATC3, UNKL, SH2B, EFCAB4B, IL21R, and TRIM14 could be related to the immune response.

\section{DISCUSSION}

MiRNA-mediated gene regulation is remarkable in many infectious diseases and affects cell processes by either mRNA degradation or translational inhibition of proteins. ${ }^{(6,7)}$ Recent studies have focused on the role of miRNAs of host cells after fungal exposure and this group of regulators can influence host responses through a variety of cellular mechanisms. ${ }^{(18)}$

Lung epithelial cells are the first line of defense of the host against inhaled Paracoccidioides spp., but the molecular pattern of these cells in response to the fungi remained unclear. Therefore, this study aimed to evaluate the miRNA profile and the potential pathways they
TABLE III

Differentially expressed miRNAs in human lung cells infected with Paracoccidioides brasiliensis 18 (Pb18)

\begin{tabular}{lcl}
\hline Upregulated & Fold change & p value \\
\hline miR-26b-3p & 3.81 & 0.0324 \\
\hline miR-27a-5p & 3.50 & 0.0388 \\
\hline miR-92a-1-5p & 3.43 & 0.0015 \\
\hline miR-149-3p & 3.17 & 0.0071 \\
\hline miR-550a-3p & 2.40 & 0.0109 \\
\hline miR-145-5p & 2.35 & 0.0030 \\
\hline miR-181a-2-3p & 2.34 & 0.0209 \\
\hline miR-941 & 2.24 & 0.0293 \\
\hline Downregulated & Fold change & p value \\
\hline miR-331-3p & 0.53 & 0.0431 \\
\hline miR-27a-3p & 0.50 & 0.0185 \\
\hline miR-185-5p & 0.44 & 0.0215 \\
\hline miR-30a-5p & 0.43 & 0.0301 \\
\hline miR-379-5p & 0.42 & 0.0118 \\
\hline miR-26b-5p & 0.42 & 0.0031 \\
\hline miR-590-5p & 0.35 & 0.0338 \\
\hline miR-30e-5p & 0.34 & 0.0381 \\
\hline miR-324-5p & 0.22 & 0.0371 \\
\hline miR-1538 & 0.15 & 0.0473 \\
\hline
\end{tabular}

regulate in lung cells exposed to Paracoccidioides spp. Surprisingly, our results showed that miRNAs expressed in lung cells were different according to the species of the fungus. Furthermore, most miRNAs were downregulated in the cells infected with $P$. lutzii, while most miRNAs were upregulated in response to $P$. americana. In the cells infected with $P$. brasiliensis, both upregulated and downregulated miRNAs were observed. The host miRNA expression signature as a response to Paracoccidioides spp. underlies the elaborate and distinct mechanism of regulation of each species. This species-specific response implies the development of more specific diagnoses and treatments for PCM. ${ }^{(19)}$ Regarding the use of miRNAs as therapeutic options, one strategy is the use of antisense oligonucleotides (antagomir) to directly block the expression of a disease-associated signature miRNA, which may be relevant for the upregulated miRNAs of lung cells in response to $P$. americana and $P$. brasiliensis. Another strategy could be the use of synthetic miRNA (miRNA mimics) to restore downregulated miRNA expression, as in the case of downregulated miRNAs of lung cells in response to $P$. lutzii and $P$. brasiliensis.

Our results also show that only five miRNAs overlapped, as demonstrated in the Venn diagram. In this context, the comparative analysis of human lung cells exposed to $\mathrm{Pb} 18$ or $\mathrm{Pa} 02$ identified miR-92a and miR941 as being common between the two fungal infections. 




Fig. 1: cell miRNAs following fungal exposure. Venn diagram with common miRNAs in A549 cells infected with the different phylogenetic lineages of the genus Paracoccidioides; P. lutzii 01 (P101), P. americana 02 ( $\mathrm{Pa} 02)$, and P. brasiliensis 18 ( $\mathrm{Pb} 18)$.

On the other hand, a set of three miRNAs (miR-26b-5p, miR-379-5p, and miR-185-5p) was common and downregulated in host cells infected with P101 or Pb18. These miRNAs have also been examined in lung cells or tissue exposed to different pathogens or injuries. Their differential expression and roles described in previous studies allow comparisons to be made and provide future direction in relation to infection by Paracoccidioides spp. For example, miR-92A was found to be upregulated in the lung tissues of 57BL/6 mice infected with A. fumigatus. (20) Another study demonstrated the miR-26b is differentially expressed in A549 cells infected with respiratory syncytial virus. ${ }^{(21)}$ Interesting, miR-26b-5p has also been detected as differentially expressed in the lungs of Balb/c mice infected with P. brasiliensis 18, which is in agreement with the present study. Furthermore, a previous study suggests a possible role of miR-26b-5p in the host immune response through the regulation of interleukin (IL)-6 expression. ${ }^{(12)}$ Regarding miR-185, a previous study showed that it is differentially expressed during oxidative stress in lung epithelial cells with injuries, and induces Bak-dependent apoptosis. ${ }^{(22)}$ This signaling pathway is also stimulated by Paracoccidioides complexes in lung cells, ${ }^{(17,23)}$ suggesting a possible regulatory role played by miRNA-186. On the other hand, in our study, miR-185, miR-379, and miR-941 were first reported to be associated with a lung fungal infection. Therefore, these miRNAs could play important roles and be potential biomarkers in PCM, contributing to speciesspecific and rapid detection of the infection.

The fact that the miRNA profile in lung cells is different, depending on the fungal species to which it has been exposed, may be due to the Paracoccidioides species showing variation in epidemiology, virulence, adaptation, and induction of the immune response in the host cells. ${ }^{(2,24,25,26)}$ Therefore, we decided to perform in silico
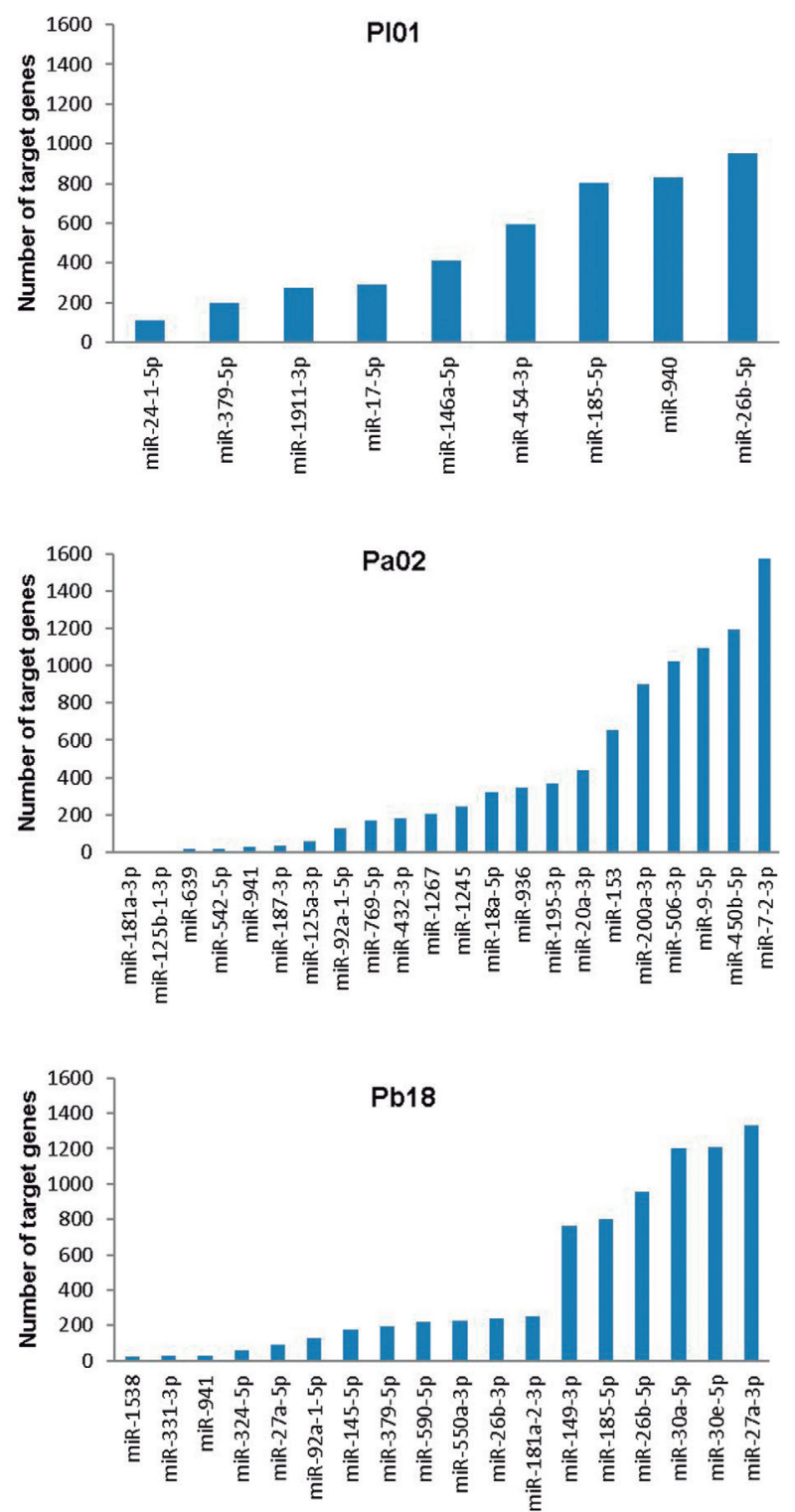

Fig. 2: quantity of predicted target genes. Number of target genes for differentially expressed miRNAs in human lung cells infected with Paracoccidioides lutzii (P101), P. americana 02 (Pa02), or P. brasiliensis 18 (Pb18).

analysis of the possible pathways regulated by the set of miRNAs in each case. We verified that although miRNAs identified in the lung cells were different according to the species studied, the potential signaling pathways regulated by miRNAs were found to be common. The identified pathways were related to the process of adhesion between the fungus and cells, the invasion process, the immune response, and the induction of apoptosis.

Previous studies have shown that the adhesion process of Paracoccidioides spp. to host extracellular matrix components such as collagen type I and IV, laminin, and fibronectin is a crucial step in the interaction. ${ }^{(23,27,28)}$ In addition, differences in the adhesion process between phylogenetic species of Paracoccidioides to A549 cells have been observed. For example, $P$. brasiliensis 18 has 
TABLE IV

Pathways related to the differentially expressed miRNAs in human lung cells infected with Paracoccidioides spp.

\begin{tabular}{|c|c|c|c|c|c|c|}
\hline \multirow[b]{2}{*}{ Pathways } & \multicolumn{2}{|c|}{ P. lutzii 01} & \multicolumn{2}{|c|}{ P. americana 02} & \multicolumn{2}{|c|}{ P. brasiliensis 18} \\
\hline & $\begin{array}{c}\text { Number of } \\
\text { miRNAs }\end{array}$ & $\mathrm{p}$ value & $\begin{array}{l}\text { Number of } \\
\text { miRNAs }\end{array}$ & $\mathrm{p}$ value & $\begin{array}{c}\text { Number of } \\
\text { miRNAs }\end{array}$ & $\mathrm{p}$ value \\
\hline \multicolumn{7}{|l|}{ Pathways in infection } \\
\hline Adherens junction & 8 & 0.000107 & 14 & 0.000000477 & - & \\
\hline Bacterial invasion of epithelial cells & 9 & 0.0000334 & 15 & 0.00835 & - & \\
\hline Endocytosis & 9 & 0.0135 & 16 & 0.000232 & - & \\
\hline Focal adhesion & - & & 16 & 0.00000836 & 16 & 0.00183 \\
\hline Gap junction & 8 & 0.0163 & 14 & 0.000233 & - & \\
\hline Phosphatidylinositol signaling system & 7 & 0.0134 & 15 & 0.00134 & - & \\
\hline Regulation of actin cytoskeleton & 8 & 0.00107 & 16 & 0.000192 & 13 & 0.000512 \\
\hline \multicolumn{7}{|l|}{ Cell signaling pathways } \\
\hline cAMP signaling pathway & - & & 16 & 0.000917 & 13 & 0.0279 \\
\hline ErbB signaling pathway & 9 & 0.00120 & 14 & 0.000186 & 13 & 0.00164 \\
\hline Hippo signaling pathway & 9 & 0.0165 & 15 & 0.00000309 & 14 & 0.000384 \\
\hline MAPK signaling pathway & - & & 20 & 0.0287 & 16 & 0.00406 \\
\hline mTOR signaling pathway & 7 & 0.0482 & 16 & 0.0275 & - & \\
\hline p53 signaling pathway & 9 & 0.00693 & - & & - & \\
\hline Rap1 signaling pathway & - & & 16 & 0.000000477 & 14 & 0.00870 \\
\hline $\mathrm{T}$ cell receptor signaling pathway & - & & 17 & 0.0189 & 14 & 0.0174 \\
\hline TGF-beta signaling pathway & 7 & 0.000989 & 16 & 0.00000161 & 15 & 0.00102 \\
\hline Wnt signaling pathway & 8 & 0.0325 & 17 & 0.00000668 & 16 & 0.0219 \\
\hline \multicolumn{7}{|l|}{ Pathway in amino acid metabolism } \\
\hline Lysine degradation & 8 & 0.00189 & 14 & 0.0189 & 10 & 0.00870 \\
\hline
\end{tabular}

shown a higher capacity for adhesion to cells and adhered more to fibronectin compared to P. lutzii, which adhered more to collagen type I and IV.(29) Consistent with these data, the present results demonstrate that most miRNAs can be associated with important early processes of PCM pathogenesis, such as focal adhesion, bacterial invasion of epithelial cells, Rap1 signaling pathway, adherens, and GAP junctions in A549, in response to Paracoccidioides. However, cells infected with $P$. lutzii presented adherens junctions and bacterial invasion of epithelial cells as the most significant pathways, while cells infected with $P$. americana 02 presented adherens junctions, the Rap1 signaling pathway, and focal adhesion, and cells infected with P. brasiliensis 18 presented only focal adhesion.

After adhesion, the entry of $P$. brasiliensis in A549 and Vero epithelial cells involves the rearrangement of cytoskeletal components of the host cells, such as actin and tubulin, with the intention of inducing pseudopodia. $(23,27)$ Once inside the host cells, pathogens favor their survival and dissemination through the induction of apop- tosis of the system immune cells. ${ }^{(30)}$ The Paracoccidioides complex induces apoptosis in macrophages and lung cells to modify the expression of caspases, Bak, and $\mathrm{Bcl}$ 2 , and consequently promotes DNA fragmentation. ${ }^{(17,23,31)}$ Similarly, our results demonstrate that most miRNAs in the lung cells infected with each of the three species of Paracoccidioides may be related to the rearrangement of the actin cytoskeleton and apoptosis through the MAPK, p53, TGF- $\beta$, and Hippo signaling pathways.

Finally, we identified miRNAs that may be related to the immune response and inflammation, such as $\mathrm{T}$ cell receptor, Wnt, MAPK, and TGF- $\beta$ signaling pathways. According to previous studies, dendritic cells and B lymphocytes stimulate $\mathrm{T}$ cells, which have an important role in the control of PCM. ${ }^{(32,33)}$ The induction of IL, cytokine, and TGF- $\beta$ levels in host cells was also observed in the interactions with Paracoccidioides spp..$^{(1,12)}$ Maza et al. also described that $P$. brasiliensis is able to activate the MAPK pathway in A549 cells, which is involved in the cytokine release by these cells as response to fungal infection. ${ }^{(34)}$ In addition, the presence of inflammation 


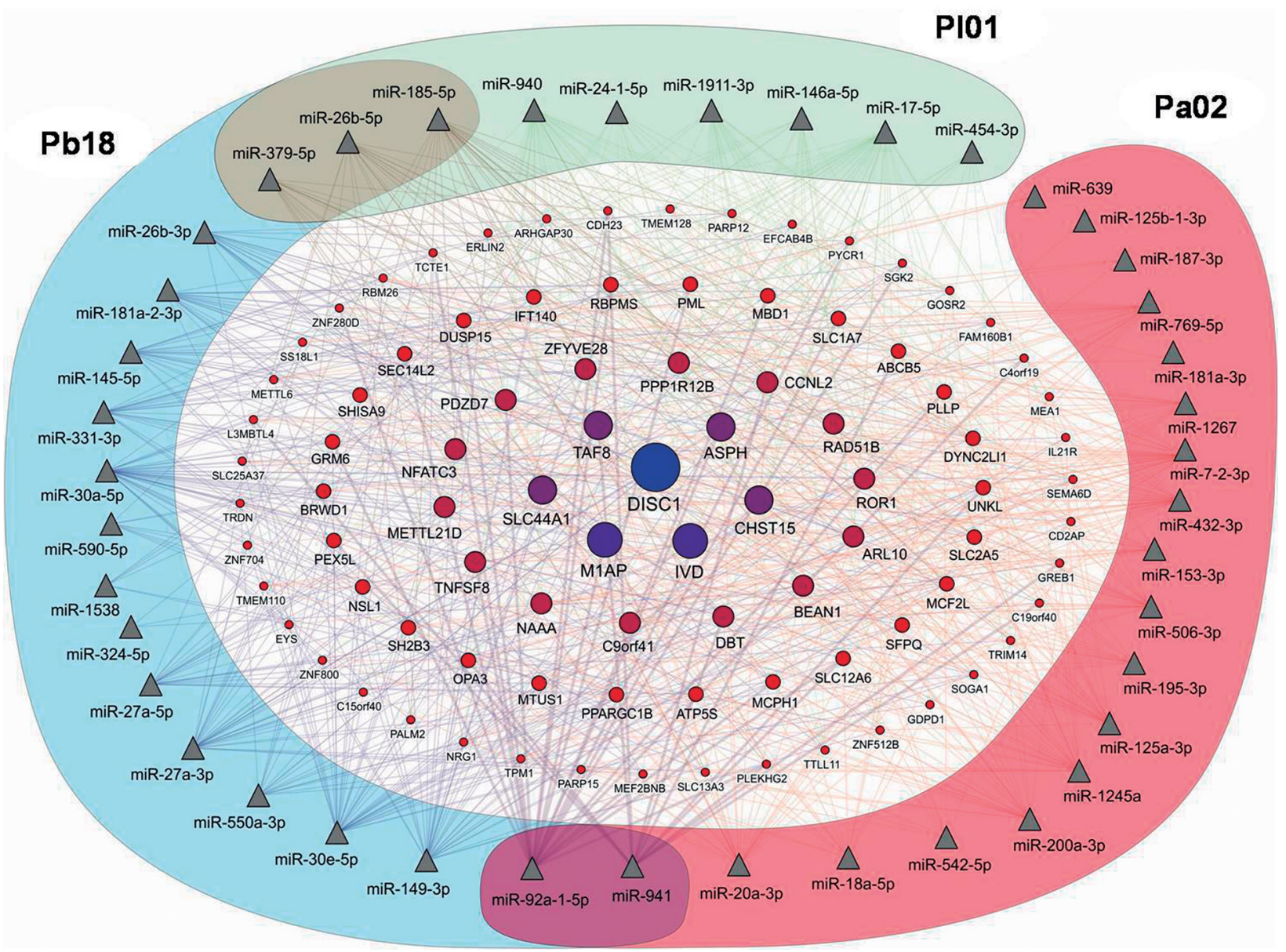

Fig. 3: miRNA-target genes interaction network. Triangles represent miRNA and circles represent predicted target genes in human lung cells infected with Paracoccidioides lutzii (P101), P. americana 02 (Pa02), or P. brasiliensis 18 (Pb18). The size of the circles is proportional to the number of miRNAs that regulate the genes.

and formation of granulomas occur in the lung tissue caused by $P$. brasiliensis infection. ${ }^{(35)}$ In the alveolar space, crosstalk between alveolar macrophages and epithelial cells can contribute to host defense. One of the molecular mechanisms that can influence this interaction is the cell-cell release of exosomal miRNAs during infections. ${ }^{(36,37,38)}$ Therefore, we believe that in addition to the miRNAs found in the lung epithelial cells, target genes involved in the response to fungi adhesion and invasion, some miRNAs can be exported to regulate genes in neighboring immune cells, contributing to the inflammatory process that occurs in PCM. Similar to the potential involvement of miRNAs in the immune response to three different species of Paracoccidioides in our in vitro model, a previous study demonstrated a set of differentially expressed miRNAs possibly involved in the in vivo immune response by analysing lungs from mice infected with $P$. brasiliensis. ${ }^{(12)}$ However, further studies are needed to validate this hypothesis.

In conclusion - This study provides the first report, to our knowledge, that identifies the miRNAs differentially expressed in human lung cells during Paracoccidioides spp. infection. Interestingly, each species (P. brasiliensis,
P. americana, and $P$. lutzii) elicited different expression profiles of miRNAs in the host cells. The results highlight the potential for detecting species-specific infections in Paracoccidioides spp., which could be useful in the diagnosis and treatment of PCM. On the other hand, the analysis of predicted targets and potential pathways suggests that the set of miRNAs from three different Paracoccidioides species stimulates similar physiological and metabolic processes, which are related to fungi adhesion and invasion and the host immune response. Further studies of validation of miRNAs and their predicted target genes found in the host cell in response to Paracoccidioides spp. could contribute to a better understanding of their role in the mechanisms of pathogenesis as well as to the development of a biomarker of PCM.

\section{AUTHORS' CONTRIBUTION}

Research idea and experimental design - JFS, FJE, AMFA and MJSMG; cell culture experiments performed - JFS; PCR experiments performed - JLS, FPG, MCC and FJE; data analysis - JLS, JFS, FPG, MCC and FJE; manuscript preparation - JLS and JFS; manuscript revision - FJE and MJSMG. All the authors have read and approved the final manuscript. The authors declare that they have no conflict of interests. 


\section{REFERENCES}

1. Shikanai-Yasuda MA, Mendes RP, Colombo AL, Queiroz-Telles F, Kono ASG, Paniago AM, et al. Brazilian guidelines for the clinical management of paracoccidioidomycosis. Rev Soc Bras Med Trop. 2017; 50(5): 715-40.

2. Teixeira MM, Theodoro RC, Nino-Vega G, Bagagli E, Felipe MS. Paracoccidioides species complex: ecology, phylogeny, sexual reproduction, and virulence. PLoS Pathog. 2014; 10(10): e1004397.

3. Muñoz JF, Farrer RA, Desjardins CA, Gallo JE, Sykes S, Sakthikumar S, et al. Genome diversity, recombination, and virulence across the major lineages of Paracoccidioides. mSphere. 2016; 1(5): e00213-16.

4. Turissini DA, Gomez OM, Teixeira MM, McEwen JG, Matute DR. Species boundaries in the human pathogen Paracoccidioides. Fungal Genet Biol. 2017; 106: 9-25.

5. Teixeira MM, Theodoro RC, de Carvalho MJ, Fernandes L, Paes $\mathrm{HC}$, Hahn RC, et al. Phylogenetic analysis reveals a high level of speciation in the Paracoccidioides genus. Mol Phylogenet Evol. 2009; 52(2): 273-83.

6. Lim LP, Lau NC, Garrett-Engele P, Grimson A, Schelter JM, Castle J, et al. Microarray analysis shows that some microRNAs downregulate large numbers of target mRNAs. Nature. 2005; 433(7027): 769-73.

7. Verma P, Pandey RK, Prajapati P, Prajapati VK. Circulating MicroRNAs: potential and emerging biomarkers for diagnosis of human infectious diseases. Front Microbiol. 2016; 7: 1274.

8. Pakshir K, Badali H, Nami S, Mirzaei H, Ebrahimzadeh V, Morovati $H$. Interactions between immune response to fungal infection and microRNAs: the pioneer tuners. Mycoses. 2019; 63(1): 4-20.

9. Monk CE, Hutvagner G, Arthur JS. Regulation of miRNA transcription in macrophages in response to Candida albicans. PLoS One. 2010; 5(10): e13669.

10. Das Gupta M, Fliesser M, Springer J, Breitschopf T, Schlossnagel H, Schmitt AL, et al. Aspergillus fumigatus induces microRNA-132 in human monocytes and dendritic cells. Int J Med Microbiol. 2014; 304(5-6): 592-6.

11. Chen H, Jin Y, Liao N, Wang Y, Chen J. MicroRNA-mediated inflammatory responses induced by Cryptococcus neoformans are dependent on the NF- $\kappa \mathrm{B}$ pathway in human monocytes. Int J Mol Med. 2017; 39(6): 1525-32.

12. Marioto DTG, Ferraro ACNS, de Andrade FG, Oliveira MB, Itano EN, Petrofeza S, et al. Study of differential expression of miRNAs in lung tissue of mice submitted to experimental infection by Paracoccidioides brasiliensis. Med Mycol. 2017; 55(7): 774-84.

13. Singulani JL, Silva JF, Gullo FP, Costa MC, Fusco-Almeida AM, Enguita FJ, et al. Preliminary evaluation of circulating microRNAs as potential biomarkers in paracoccidioidomycosis. Biomed Rep. 2017; 6(3): 353-7.

14. Livak KJ, Schmittgen TD. Analysis of relative gene expression data using real-time quantitative PCR and the 2(-Delta Delta C(T)) method. Methods. 2001; 25(4): 402-8.

15. Paraskevopoulou MD, Georgakilas G, Kostoulas N, Vlachos IS, Vergoulis T, Reczko M, et al. DIANA-microT web server v5.0: service integration into miRNA functional analysis workflows. Nucleic Acids Res. 2013; 41(Web Server issue): W169-73.

16. Kanehisa M, Goto S. KEGG: kyoto encyclopedia of genes and genomes. Nucleic Acids Res. 2000; 28(1): 27-30.

17. Del Vecchio A, De Fátima Da Silva J, da Silva JL, Andreotti PF, Soares CP, Benard G, et al. Induction of apoptosis in A549 pulmonary cells by two Paracoccidioides brasiliensis samples. Mem Inst Oswaldo Cruz. 2009; 104(5): 749-54.
18. Croston TL, Lemons AR, Beezhold DH, Green BJ. MicroRNA regulation of host immune responses following fungal exposure. Front Immunol. 2018; 9: 170.

19. Drury RE, O'Connor D, Pollard AJ. The clinical application of microRNAs in infectious disease. Front Immunol. 2017; 8: 1182.

20. Chen F, Xu XY, Zhang M, Chen C, Shao HT, Shi Y. Deep sequencing profiles microRNAs related to Aspergillus fumigatus infection in lung tissues of mice. J Microbiol Immunol Infect. 2019; 52(1): 90-9.

21. Bakre A, Mitchell P, Coleman JK, Jones LP, Saavedra G, Teng $\mathrm{M}$, et al. Respiratory syncytial virus modifies microRNAs regulating host genes that affect virus replication. J Gen Virol. 2012; 93(Pt 11): 2346-56.

22. Zhang D, Lee H, Cao Y, Dela Cruz CS, Jin Y. miR-185 mediates lung epithelial cell death after oxidative stress. Am J Physiol Lung Cell Mol Physiol. 2016; 310(7): L700-10.

23. Mendes-Giannini MJ, Hanna SA, da Silva JL, Andreotti PF, Vincenzi LR, Benard G, et al. Invasion of epithelial mammalian cells by Paracoccidioides brasiliensis leads to cytoskeletal rearrangement and apoptosis of the host cell. Microbes Infect. 2004; 6(10): 882-91.

24. Carvalho KC, Ganiko L, Batista WL, Morais FV, Marques ER, Goldman GH, et al. Virulence of Paracoccidioides brasiliensis and gp43 expression in isolates bearing known PbGP43 genotype. Microbes Infect. 2005; 7(1): 55-65.

25. Matute DR, McEwen JG, Puccia R, Montes BA, San-Blas G, Bagagli E, et al. Cryptic speciation and recombination in the fungus Paracoccidioides brasiliensis as revealed by gene genealogies. Mol Biol Evol. 2006; 23(1): 65-73.

26. Siqueira IM, Fraga CL, Amaral AC, Souza AC, Jeronimo MS, Correa JR, et al. Distinct patterns of yeast cell morphology and host responses induced by representative strains of Paracoccidioides brasiliensis (Pb18) and Paracoccidioides lutzii (Pb01). Med Mycol. 2016; 54(2): 177-88.

27. Mendes-Giannini MJ, Monteiro da Silva JL, De Fatima Da Silva J, Donofrio FC, Miranda ET, Andreotti PF, et al. Interactions of Paracoccidioides brasiliensis with host cells: recent advances. Mycopathologia. 2008; 165(4-5): 237-48.

28. Mendes-Giannini MJ, Andreotti PF, Vincenzi LR, da Silva JL, Lenzi HL, Benard G, et al. Binding of extracellular matrix proteins to Paracoccidioides brasiliensis. Microbes Infect. 2006; 8(6): 1550-9.

29. de Oliveira HC, da Silva JF, Scorzoni L, Marcos CM, Rossi SA, de Paula E Silva AC, et al. Importance of adhesins in virulence of Paracoccidioides spp. Front Microbiol. 2015; 6: 303.

30. Weinrauch Y, Zychlinsky A. The induction of apoptosis by bacterial pathogens. Annu Rev Microbiol. 1999; 53: 155-87.

31. Silva SS, Tavares AH, Passos-Silva DG, Fachin AL, Teixeira SM, Soares CM, et al. Transcriptional response of murine macrophages upon infection with opsonized Paracoccidioides brasiliensis yeast cells. Microbes Infect. 2008; 10(1): 12-20.

32. Thind SK, Taborda CP, Nosanchuk JD. Dendritic cell interactions with Histoplasma and Paracoccidioides. Virulence. 2015; 6(5): 424-32.

33. Ferreira KS, Bastos KR, Russo M, Almeida SR. Interaction between Paracoccidioides brasiliensis and pulmonary dendritic cells induces interleukin-10 production and toll-like receptor-2 expression: possible mechanisms of susceptibility. J Infect Dis. 2007; 196(7): 1108-15.

34. Maza PK, Oliveira P, Toledo MS, Paula DM, Takahashi HK, Straus AH, et al. Paracoccidioides brasiliensis induces secretion of IL-6 and IL- 8 by lung epithelial cells. Modulation of host cytokine levels by fungal proteases. Microbes Infect. 2012; 14(12): 1077-85. 
35. Da Silva FC, Svidzinski TI, Patussi EV, Cardoso CP, De Oliveira Dalalio MM, Hernandes L. Morphologic organization of pulmonary granulomas in mice infected with Paracoccidioides brasiliensis. Am J Trop Med Hyg. 2009; 80(5): 798-804.

36. Maemura T, Fukuyama S, Sugita Y, Lopes TJS, Nakao T, Noda $\mathrm{T}$, et al. Lung-Derived exosomal miR-483-3p regulates the innate immune response to influenza virus infection. J Infect Dis. 2018; 217(9): $1372-82$.
37. Lee H, Abston E, Zhang D, Rai A, Jin Y. Extracellular vesicle: an emerging mediator of intercellular crosstalk in lung inflammation and injury. Front Immunol. 2018; 9: 924.

38. Yuan Z, Petree JR, Lee FE, Fan X, Salaita K, Guidot DM, et al. Macrophages exposed to HIV viral protein disrupt lung epithelial cell integrity and mitochondrial bioenergetics via exosomal microRNA shuttling. Cell Death Dis. 2019; 10(8): 580. 